\title{
Special Issue: The Fossil-Lagerstätte Enspel - exceptional preservation in an Upper Oligocene maar
}

Published online: 21 November 2009

(C) Senckenberg, Gesellschaft für Naturforschung and Springer 2009

Palaeobiodiversity and Palaeoenvironments issue 1, volume 90 will be a Special Issue on the Fossil-Lagerstätte of Enspel (Westerwald Mountains of western Germany). This site is well known for the exceptional preservation of its fossil biota. Enspel is a key Lagerstätte for the Upper Oligocene, a period in Central Europe characterised by global climatic deterioration accompanied by prominent vegetational changes. Research has been carried out at this site for more than 20 years, and this issue provides a review of the current state of knowledge on this important site as well as new data on the volcanogenic and sedimentologic development of Lake Enspel. The articles included in the Special Issue report on a variety of different areas of current palaeontological research, including palaeoclimate estimates based on fossil plants, the palaeoecology of organic-walled algae, palaeobiogeographic and palaeoclimatic implications of fossil insects, amphibians and crocodiles and a description of a new species of Amphilagus, the oldest European lagomorph. As such, this Special Issue provides a state-of-the-art overview of many aspects of this important Lagerstätte. 